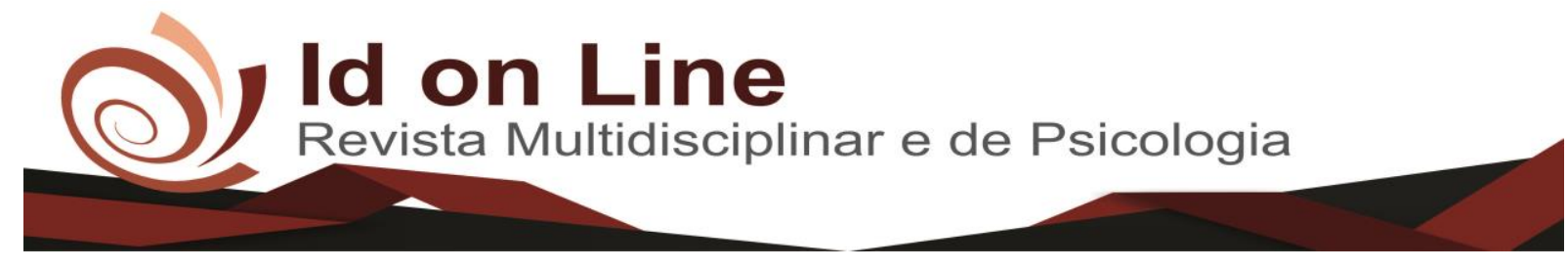

DOI: $10.14295 /$ idonline.v13i48.2227

Artigo

\title{
Experiências da Ambientação do Programa Residência Pedagógica: Conhecendo na Prática
}

\author{
Damiana Filgueira da Silva'; Wêdya Gabriely Pereira Canuto ${ }^{2}$ : Maria das Graças de Oliveira Bento ${ }^{3}$
}

\begin{abstract}
Resumo: O presente trabalho tem como principal objetivo mostrar vivências que ocorreram em um estágio/residência pelo PRP - Programa Residência Pedagógica, o mesmo tem se mostrado de grande importância e positivo para a formação docente, o programa foi um grande avanço para a FACHUSC - Faculdade de Ciências Humanas do Sertão Central, uma parceria em prol do aperfeiçoamento dos licenciandos em Pedagogia e Ciências Biológicas, e por meio deste trabalho pode-se perceber a real importância do Programa. A residência aconteceu na escola Dr. Severino Alves de Sá, localizada em Salgueiro- PE e foi realizado em duas fases, Ambientação e Imersão e foi a ponte principal para conseguir chegar a tanto conhecimento. Através da residência, pode-se perceber a importância da gestão escolar e do PPP-Projeto Político Pedagógico da escola. Transformar um ambiente educativo não é fácil, pois requer muita paciência para saber lidar com problemas, ter a prática necessária para poder trabalhar o conjunto e ter didática para transformar as expectativas em realidades. Nada é fácil quando tudo esta ao pé da letra, pois mesmo que tudo seja tranquilidade no ambiente administrativo, sempre vai haver uma pedrinha na qual o gestor terá que resolver, neste caso fica claro a importância de uma gestão escolar e do Projeto Político Pedagógico-PPP, que é um documento organizador de uma instituição escolar, esses novos programas estão vindo para somar juntamente com a escola e transformar a educação. Este trabalho tem abordagem qualitativa, com pesquisa bibliográfica através de estudos realizados por teóricos como: Libâneo (2005), Veiga (2002) e Tardif (2008). Todas as fases do PRP foram realizadas com grande sucesso. Cada uma proporcionou conhecimentos específicos. Certamente o Programa fortaleceu a parceria entre a universidade e a escola campo de residência, culminado no aperfeiçoamento da prática docente.
\end{abstract}

Palavras-Chave: Programa Residência Pedagógica, Formação docente, Aperfeiçoamento.

\section{Program Environment Experiences Pedagogical Residence: Knowing in Practice}

\begin{abstract}
The present work has as main objective to show experiences that occurred in an internship / residency by the PRP - Pedagogical Residency Program, it has been of great importance and positive for the teacher formation, the program was a great advance for FACHUSC - Faculty of Human Sciences of the Central Sertão, a partnership for the improvement of graduates in Pedagogy and Biological Sciences, and through this work one can realize the real importance of the Program. The residency took place at Dr. Severino Alves de Sá School, located in Salgueiro-PE and was carried out in two phases, Ambientação and Immersão and was the main bridge to achieve such knowledge. Through residency, one can realize the importance of school management and the PPP-Pedagogical Political Project of the school. Transforming an educational environment is not easy, because it requires a lot of patience to know how to deal with problems, have the necessary practice to be able to work together and didactics to turn expectations into realities. Nothing is easy when everything is to the letter, because even if everything is quiet in the administrative environment, there will always be a pebble in which the manager will have to solve, in this case it is clear the importance of school management and the Pedagogical-Political Project. PPP, which is an organizing document for a school institution, these new programs are coming to add together with the school and transform education. This work has a qualitative approach, with bibliographic research through studies by theorists such as: Libâneo (2005), Veiga (2002) and Tardif (2008). All phases of the PRP were performed with great success. Each provided specific knowledge. Certainly, the Program strengthened the partnership between the university and the field of residence school, culminating in the improvement of teaching practice.
\end{abstract}

Keywords: Pedagogical Residency Program, Teacher Training, Improvement.

\footnotetext{
${ }^{1}$ Graduanda em licenciatura em Pedagogia, FACHSUC, damiananenem88513491@gmail.com;

${ }^{2}$ Graduada em licenciatura em Pedagogia, FACHUSC, Wedja.gaby@ hotmail.com;

${ }^{3}$ Mestra, Universidade Católica de Pernambuco, professoragracabenco@ hotmail.com . 


\section{Introdução}

O presente trabalho tem como objetivo relatar as vivências da residência pedagógica realizada na escola Municipal Dr. Severino Alves de Sá na cidade de Salgueiro PE, localizada no bairro do Planalto, tendo por finalidade observar as atividades desenvolvidas na secretaria da escola e comunidade escolar, conhecer a parte pedagógica, administrativa e financeira, e as principais atividades da gestão escolar.

O mesmo se dar por meio do Programa de Residência Pedagógica (PRP) que faz parte da Coordenação de Aperfeiçoamento de Pessoal do Nível Superior (CAPES), do Ministério da Educação, em parceria com Faculdade de Ciências Humanas do Sertão Central (FACHUSC), beneficiando os cursos de Pedagogia e Ciências Biológicas.

A residência proporcionou aos alunos, vivências impares que contribuíram positivamente na suas graduações, o mesmo foi desenvolvido em cima de estudos do Projeto Político Pedagógico (PPP) da escola campo de estágio, pode-se perceber o trabalho de todas as áreas em conjunto com o mesmo. O PRP tem sido uma ponte para o conhecimento e aperfeiçoamento de graduandos.

O Programa de Residência Pedagógica surgiu para que as práticas dos graduandos em licenciaturas fossem vivenciadas, orientadas e assistidas. Após seleção, os residentes foram encaminhados para as escolas campo de estágio parceiras do programa. Umas das escolas foi a Dr. Severino Alves de Sá, no município de Salgueiro- PE, recebeu vários residentes, muito bem acolhidos para o início da primeira fase. O Diretor da escola, José Aribamar de Assis Campos, juntamente com toda sua equipe, apresentou a instituição, nos dando carta branca para iniciarmos os trabalhos de 40 horas.

Para Libâneo (2005):

“O diretor não pode ater-se apenas às questões administrativas. Como dirigente, cabelhe ter uma visão de conjunto e uma atuação que apreenda a escola em seus aspectos pedagógicos, administrativos, financeiros e culturais" (LIBÂNEO, 2005, p.332).

A gestão demonstrou-se interessada em acolher os residentes e colaborar com o Programa de Residência Pedagógica, facilitando a observação e a análise da instituição assim como o trabalho realizado em diversos setores.

492 Id on Line Rev. Mult. Psic. V.13, N. 48 p. 491-504, Dezembro/2019 - ISSN 1981-1179 
O percurso metodológico organizou-se a partir da socialização em duas pequenas reuniões com a professora preceptora Wedya Gabrielly Pereira Canuto, na qual ela explicou um pouco sobre a cadeira e como devemos observar para assim se adequar a área, para ambos termos um conhecimento inerente ao assunto. Os métodos aplicados para a compressão da gestão escolar num estágio onde um graduando pouco conhece em ações, foi também através de estudos, onde o curso oferece uma cadeira na qual ganhamos conhecimento e facilidade de manusear as atividades com mais entendimento, porem o que nos fornece um grande aprendizado são as observações dentre cada passo dado na sala gestora.

Os estágios se deram por meio de conversação e observação da estrutura escolar, foi observada também o quadro de funcionários, e o quadro de docentes, encontraram funcionários qualificados para desempenhar suas funções e responsáveis pelo que faz, o estágio pode nus mostrar a importância de uma gestão escolar e o quanto é uma função de muita dedicação e compromisso.

\section{Descrição geográfica e física da escola}

Na primeira visita a escola campo de estágio para a realização do programa de residência, pode-se conhecê-la geograficamente, e em sua estrutura física, onde a excelência e a determinação dos funcionários em nos atender e proporcionar um bom estágio era extraordinária.

A Escola Doutor Severino Alves de Sá, é uma escola pública, que proporciona desde o Ensino Fundamental Anos Inicias, como Anos Finais. Localizada na cidade de Salgueiro- PE, Rua Espedita de Sá Araújo, S/N, no bairro do Planalto, CEP: 56 000-000, Fone: (087) 3871 7044, email para contato: escolaseverinosa@hotmail.com. Possui em seu interior 10 salas de aulas, 1 sala de leitura, 1 cantina, 1 secretaria, 1 sala de informática, 1 sala de AEE-Atendimento Educacional Especializado, 4 banheiros, quadra poliesportiva, sala dos professores, diretoria e depósito, para maior desempenho profissional e estudantil

Seu quadro de funcionários conta com 2 auxiliares administrativos, 22 professores, 14 mediadores / auxiliares de crianças com deficiência e 5 auxiliares de limpeza. A sala de AEE, oferece dentro do seu processo de formação e acompanhamento dos alunos, Cursos de Libras,

493 Id on Line Rev. Mult. Psic. V.13, N. 48 p. 491-504, Dezembro/2019 - ISSN 1981-1179 
cursos da língua escrita para alunos com deficiência, cursos de uso da informática acessível, cursos de comunicação alternativa e aumentativa, cursos do uso de recursos ópticos e não ópticos, cursos para autonomia na escola, cursos para alunos com deficiências, cursos para o desenvolvimento de processos mentais, e cursos de capacitação em orientação e mobilidade.

Vale ressaltar que a escola ainda conta com um parque infantil, a fim de ter momentos de recreação mais prazerosos, assim como internet banda larga, para maior desenvolvimento profissional, visando o desenvolvimento educacional do aluno.

Foram realizadas diversas observações, sendo todas elas anotadas, dados como: quantidade de alunos matriculados, salas, banheiros e outros ambientes. Observamos o Projeto Político Pedagógico da escola, que é de grande importância para o andamento da instituição. Nele pode-se observar que a escola é de máxima qualidade em questão de estrutura e ensino, pois o PPP de uma escola deve conter planos e ações vivenciadas ou em seu processo de desenvolvimento, e a escola Dr. Severino contempla informações posta em realidade em seu ambiente escolar.

Conforme Veiga (2002, p.02), o Projeto Político Pedagógico tem a ver com organização do trabalho pedagógico em dois níveis: organização da escola como um todo e, organização da sala de aula. Essa organização é de fácil visão na escola parceira do PRP, adotou a sua Política Pedagógica em termos de gestão, onde seu projeto permite a melhor maneira a ser trabalhar no processo de ensino aprendizagem do ensino Fundamental Anos Iniciais.

Além da análise do projeto, podemos vivenciar na prática a organização gestacional de uma secretaria no seu dia a dia, onde desenvolvemos atividades planejadas pelos professores para a realização dos alunos em sala, matrículas de novatos para engajamentos de novas vivências na escola, desenvolvimento de transferências e entrega de boletos com respectivas notas dos alunos, que por sua vez dão um show em sabedoria e conhecimentos adquiridos por intermédio dos bons profissionais da instituição de ensino.

\section{Organização e Planejamento na Prática}

Para se ter um bom rendimento do aluno, o transformando em um formador de opiniões

494 Id on Line Rev. Mult. Psic. V.13, N. 48 p. 491-504, Dezembro/2019 - ISSN 1981-1179 Edição eletrônica em http://idonline.emnuvens.com.br/id 
incluso em uma sociedade, ocorre um processo de organização e planejamento que vem desde uma simples indagação, como ate mesmo um grande projeto, na qual a escola toma para sim e desenvolve como objeto de ensino aos alunos.

O Programa Residência Pedagógica, também nos proporcionou uma maior interação com a equipe de ensino da escola Dr. Severino, onde pode-se observar que mediante planejamento, a prática em sala de aula é de encantar o ser humano, pois os mesmo disponibiliza ao alunos meios de aprendizagem qualificada, que mesmo tendo as especificidades de realidades de sala, as professoras se adaptam a tal realidade, e continua o processo de aplicação do planejamento.

Observa-se que segundo Tardif (2000), o trabalho do professor se dá de uma ação em uma situação social em que exige competências e uma interação crescente com a vida profissional. O autor apenas enfatiza o que muitos sabem, e veem a descobrir mediante prática ativa em estágio supervisionado, pois é através dele que os futuros profissionais da educação chegam em sala com uma formação inicial do que se diz respeito ao lecionar alunos com especificidades diferentes.

Tardif (2008) reforça a concepção do estágio na formação do profissional de educação quando ele relata que, é chamada a atenção para o momento chave que constitui a formação inicial e a inserção na carreira docente, no sentido forte do termo "estágio".

Conforme a visão de estágio de Tardif, estamos em grande vantagem na nossa formação profissional, pois o PRP - Programa de Residência Pedagógica, através do Edital CAPES (06/2018), explana que:

2.-2.1 I. Aperfeiçoar a formação dos discentes de cursos de licenciatura, por meio do desenvolvimento de projetos que fortaleçam o campo da prática e conduzam o licenciando a exercitar de forma ativa a relação entre teoria e prática profissional docente, utilizando coleta de dados e diagnóstico sobre o ensino e a aprendizagem escolar, entre outras didáticas e metodologias; (EDITAL CAPES 06/2018, p 01).

A formação do professor dentro de suas ações em conflito com a realidade, distinguirá como será o futuro profissional da educação, e o PRP vem justamente pra promover essa prática visionaria nas instituições docentes, que é onde se inicia todo processo de aprendizagem do universitário. 
Buscamos trabalhar dentro da sala de aula as necessidades vistas durante o processo de ambientação escolar, onde podemos perceber uma grande deficiência na leitura e escrita dos alunos, em parceria com o professor regente da turma, buscamos trazer esses alunos para uma realidade diferente, onde mostramos para eles uma forma diferente e dinâmica de se aprender a fazer algo que não é tão complicado.

Nesse momento iniciamos os projetos de intervenções, buscando trabalhar de acordo com as necessidades do alunado. Um dos principais problemas foi a leitura, ainda estamos em processo, pois tratamos de alunos que não são alfabetizados, ou não foram alfabetizados na idade correta, isso não tem sido algo muito fácil, mas podemos afirmar que está sendo algo gratificante, pois a cada dia algo de conhecimento se acrescenta na nossa vida acadêmica.

Durante o projeto aplicado, tiramos de sala de aula apenas aqueles alunos que apresentavam muitas dificuldades, levamos para uma outra sala de aula, onde lá podemos trabalhar melhor na alfabetização desses alunos.

\section{Metodologia}

Este trabalho tem abordagem qualitativa, com pesquisa bibliográfica. O caderno etnográfico foi de grande contribuição para as anotações diárias que contribuíram posteriormente para o desenvolvimento deste trabalho.

No caderno etnográfico foram relatados todos os acontecimentos da residência, buscando mostrar algo que foi desempenhado com qualidade. Nesses momentos de residência buscou-se trabalhar com materiais da própria escola, usou-se também materiais que foram criados pelos residentes, em busca de chamar a atenção do alunado, dentre todas as coisas os jogos sensoriais foram motivacionais para cada dia de residência, pois era por meio deles que os residentes chegavam até as dificuldades.

Foram necessários vários momentos para a realização das pesquisas e observações até chegarmos a uma reta de desenvolvimento, buscamos continuar com os projetos sociais que tem nos ajudado bastante nessas etapas de ambientação escolar e imersão.

496 Id on Line Rev. Mult. Psic. V.13, N. 48 p. 491-504, Dezembro/2019 - ISSN 1981-1179 


\section{Resultados e Discussão}

Alcançamos muitos objetivos, conhecimentos e experiências e os grandes aprendizados aconteceram através de interação com todos os funcionários, que experientes, facilitaram todos os trabalhos dos residentes, direcionando todas as ações. Também foi observado que, além de possuir um quadro de funcionários competentes, os mesmos praticam bons relacionamentos com a comunidade.

Com muita dedicação e esforço, todos os objetivos foram alcançados e todas as metas cumpridas. Participamos de grandes atividades que nos proporcionaram crescimento e aprendizagens, como: renovação de matrículas, transferências de alunos e vários tipos de declarações, correção de diários, entrega de boleto dos alunos.

Passamos a conhecer um documento escolar importante, o PPP - Projeto Político Pedagógico, pois antes, o conhecíamos apenas em aulas teóricas, com ele em mãos, constatamos a relevância de suas normas e orientações para conduzir a escola. Ao analisarmos o PPP da escola Dr. Severino Alves de Sá, percebemos que é um instrumento educativo e através dele, podemos aprimorar as informações acadêmicas por meio de análises e observações.

O PRP nos proporcionou dois minicursos, o primeiro de Produção textual e o segundo sobre Oratória, ambos de grande importância para a vida acadêmica e também para o PRP, tendo em vista que o programa existe a produção de relatórios, resumos e artigo. Agradecemos ao coordenador do programa Pedro Fernando dos Santos, a orientadora Maria das Graças Bento, e à preceptora Wedya Gabriele Pereira Canuto, assim como toda a equipe da escola Dr. Severino Alves de Sá.

Todos os momentos foram importantes, mas os vividos em sala de aula foram os mais significativos para o residente, pois é o ambiente que estaremos quando finalizarmos o curso e começarmos o exercício docente. Certamente a prática do ensino foi realizada e será aprofundada à medida que a docência for sendo exercitada.

Segue abaixo momentos vivenciados na escola campo de residência Dr. Severino Alves de Sá. Imagens marcantes para a residência, pois cada momento expressa uma aprendizagem: 
Foto 1: Relatos no Caderno Etnográfico

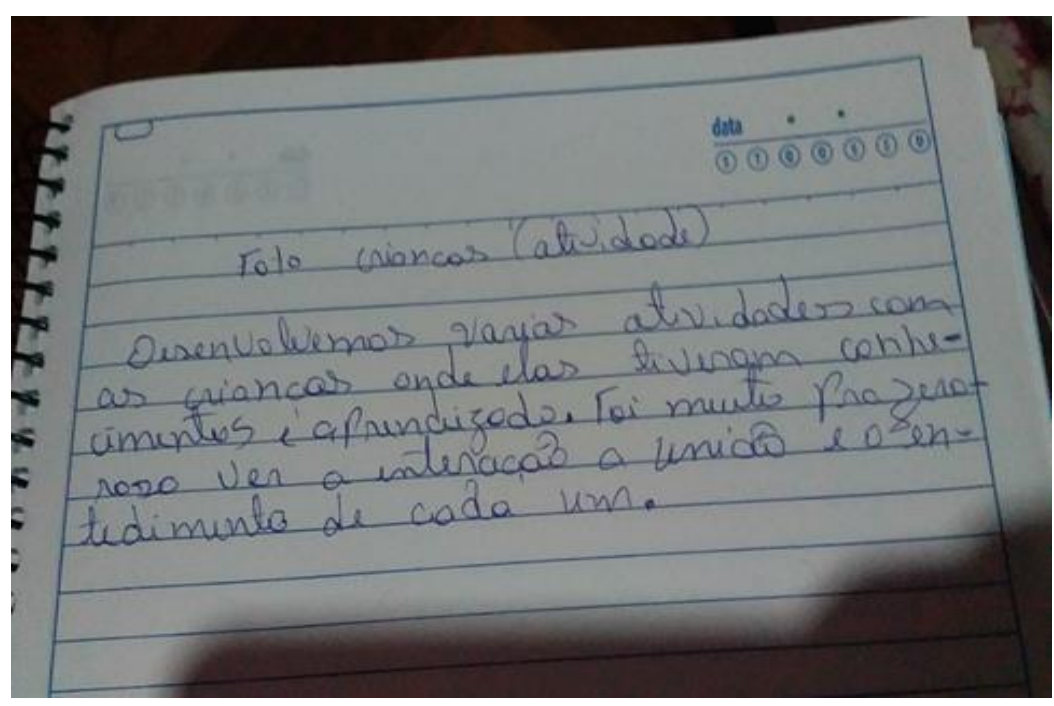

Fonte: Arquivo pessoal

Foto 2: Relatos no Caderno Etnográfico

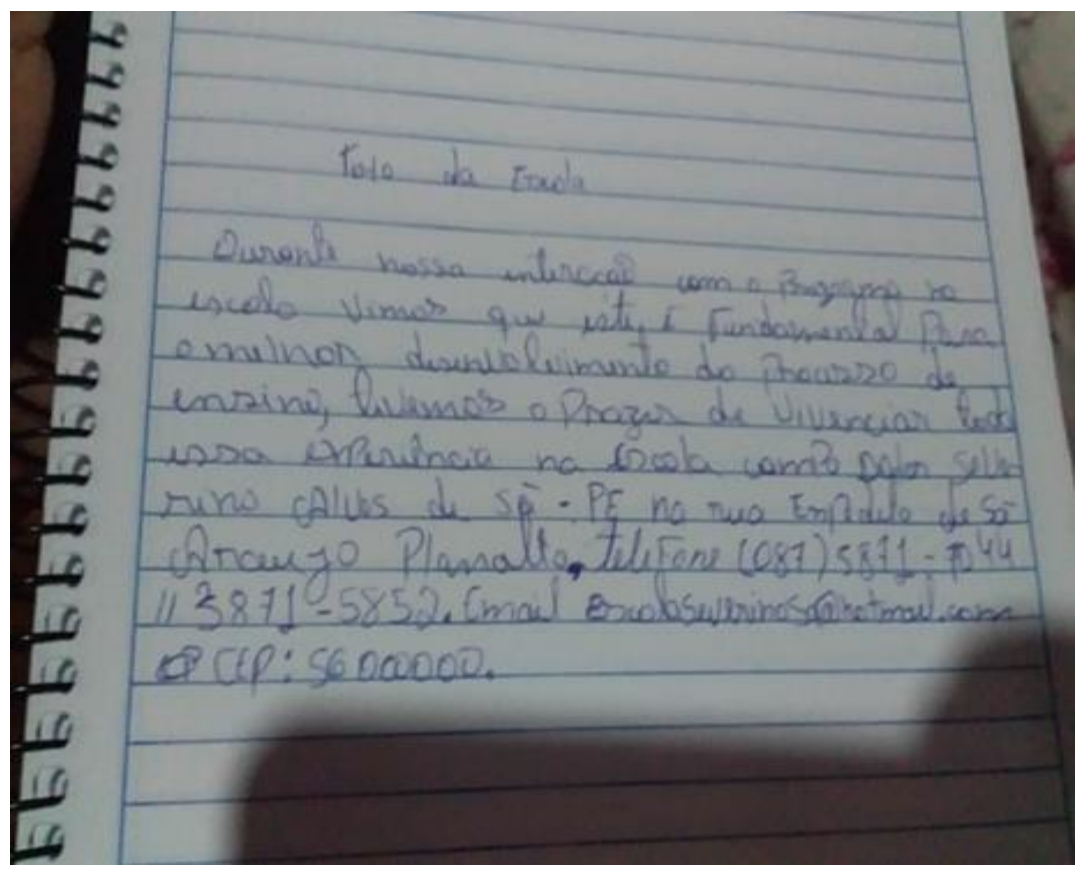

Fonte: Arquivo pessoal 
Foto 3: Fase de Ambientação, conhecendo a secretaria escolar.

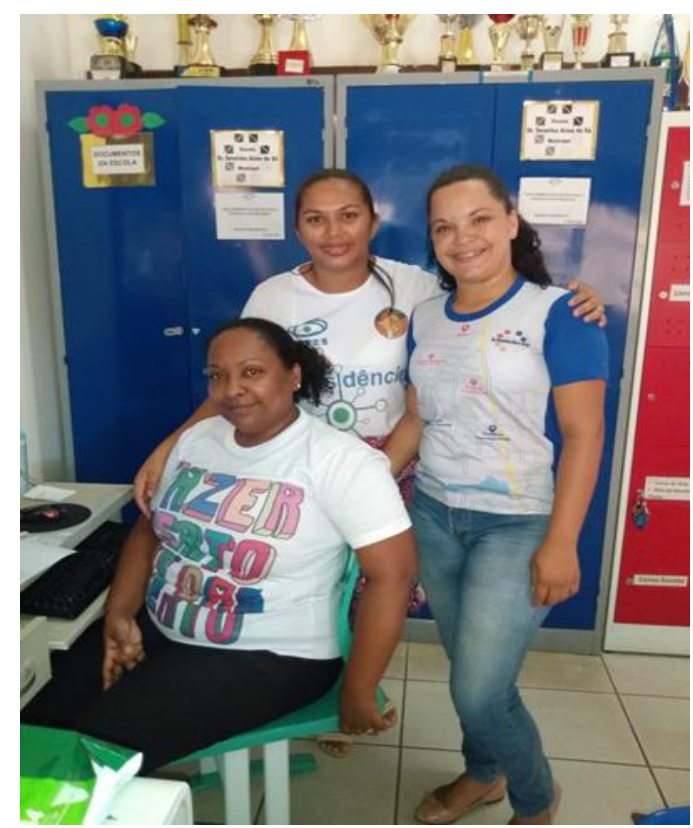

Fonte: Arquivo pessoal

Foto 4: Fase de Ambientação, recebendo orientações.

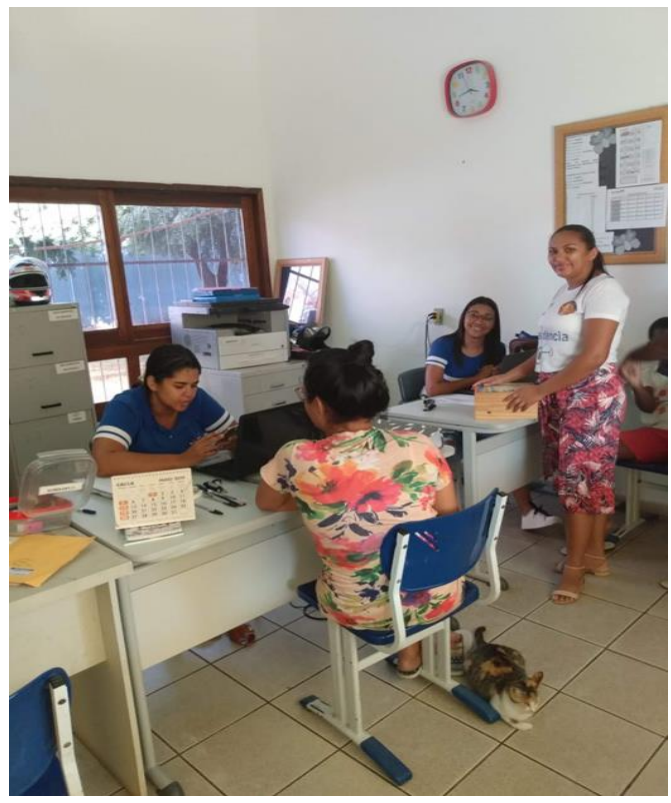

Fonte: Arquivo pessoal 
Foto 5: Fase de Ambientação, residentes compartilhando informações.

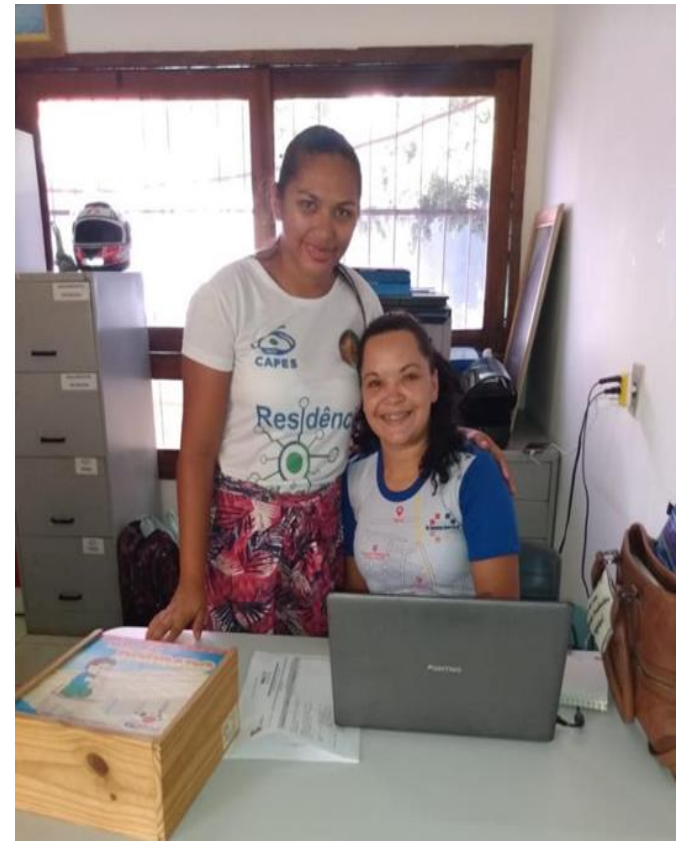

Fonte: Arquivo pessoal

Foto 6: Fase de Imersão, palestra com os pais dos alunos sobre nutrição e saúde mental.

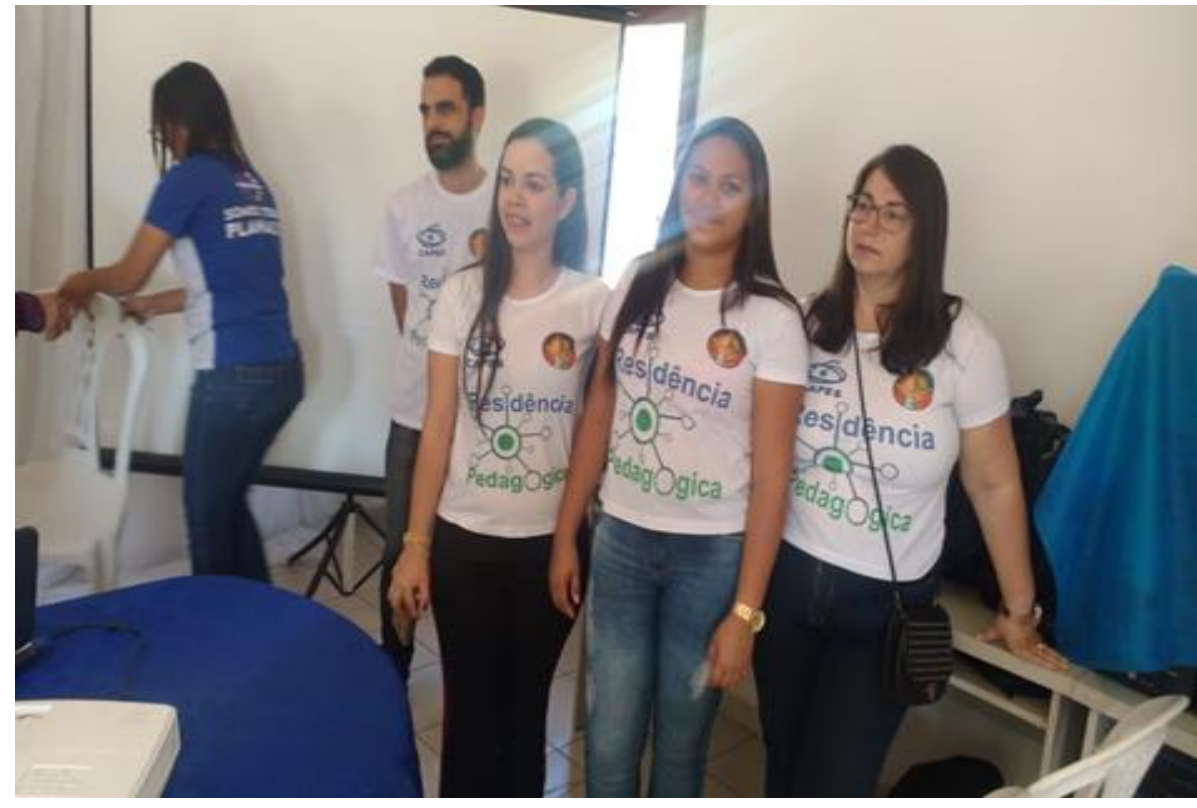

Fonte: Arquivo pessoal 
Foto 7: Fase de Imersão, atividades lúdicas.

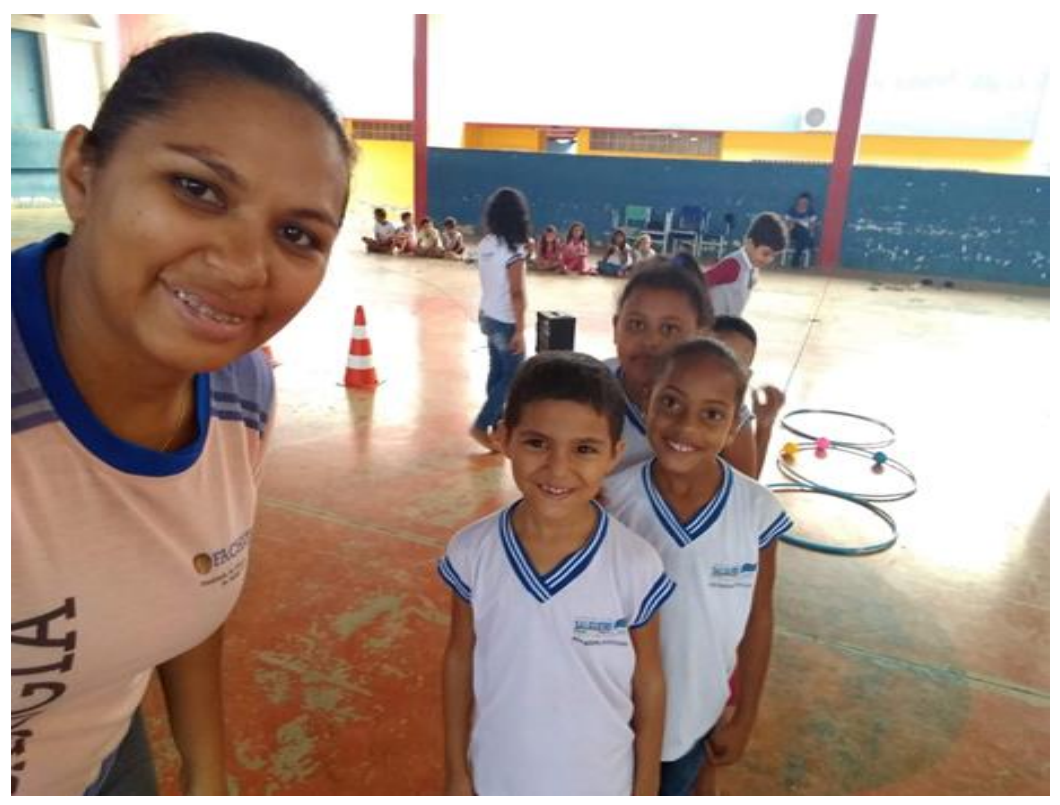

Fonte: Arquivo pessoal

Foto 8: Fase de Imersão, reforçando a aprendizagem.

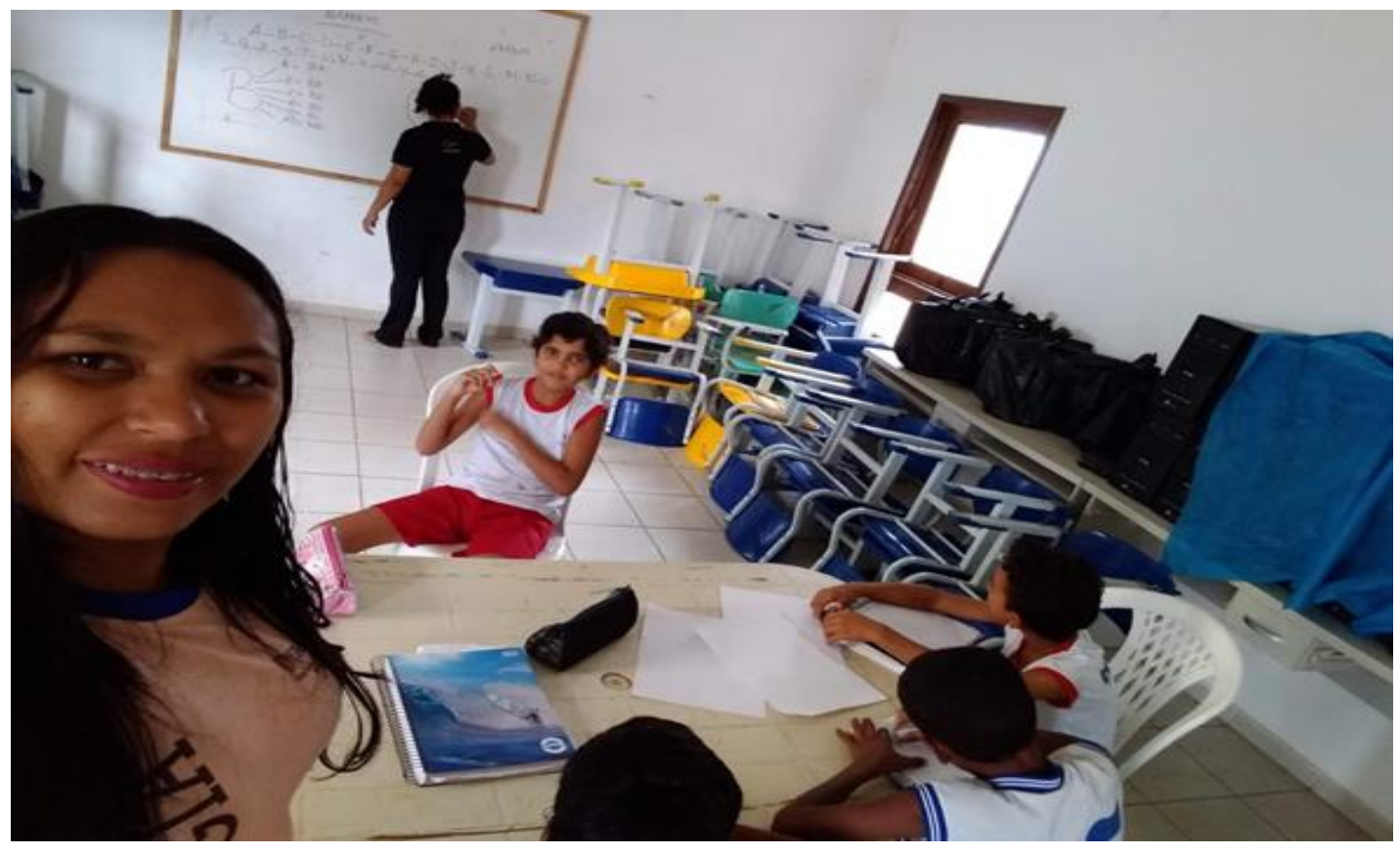

Fonte: Arquivo pessoal

501 Id on Line Rev. Mult. Psic. V.13, N. 48 p. 491-504, Dezembro/2019 - ISSN 1981-1179 Edição eletrônica em http://idonline.emnuvens.com.br/id 
Foto 9: Fase de Imersão, reforçando a aprendizagem.

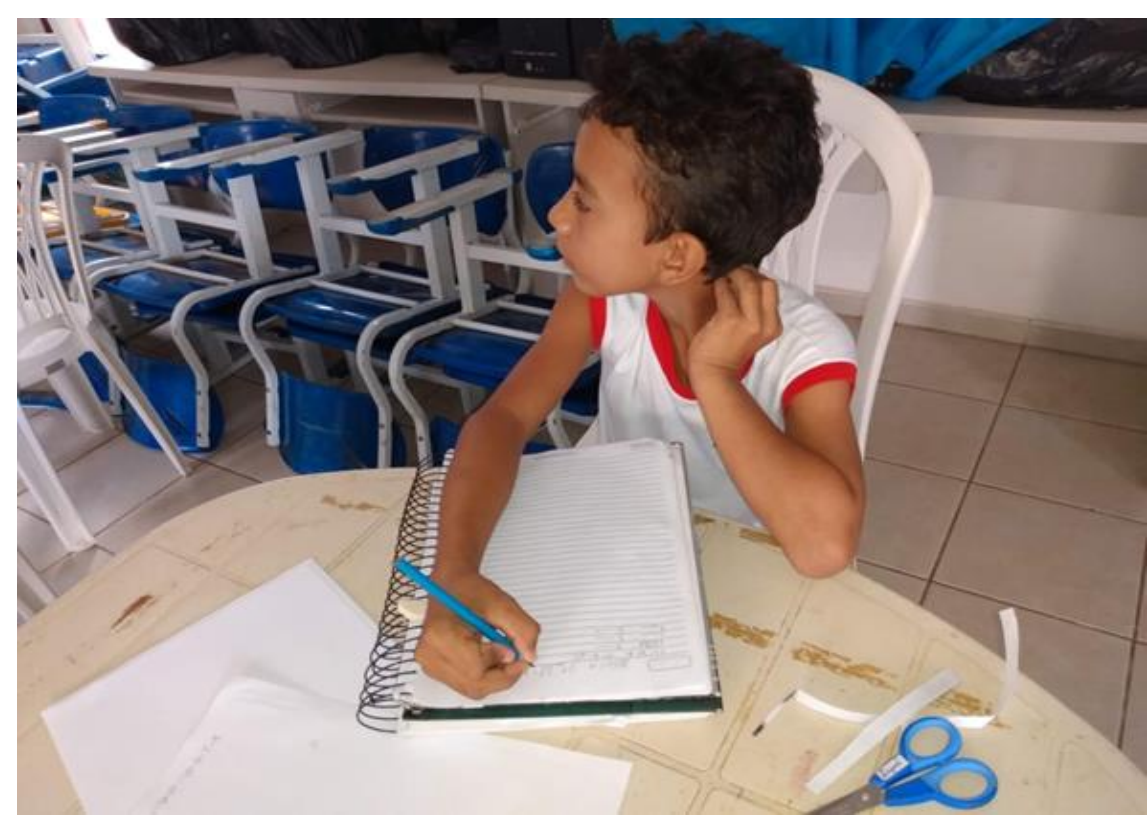

Fonte: Arquivo pessoal

Foto 10: Fase de Imersão, reforçando a aprendizagem.

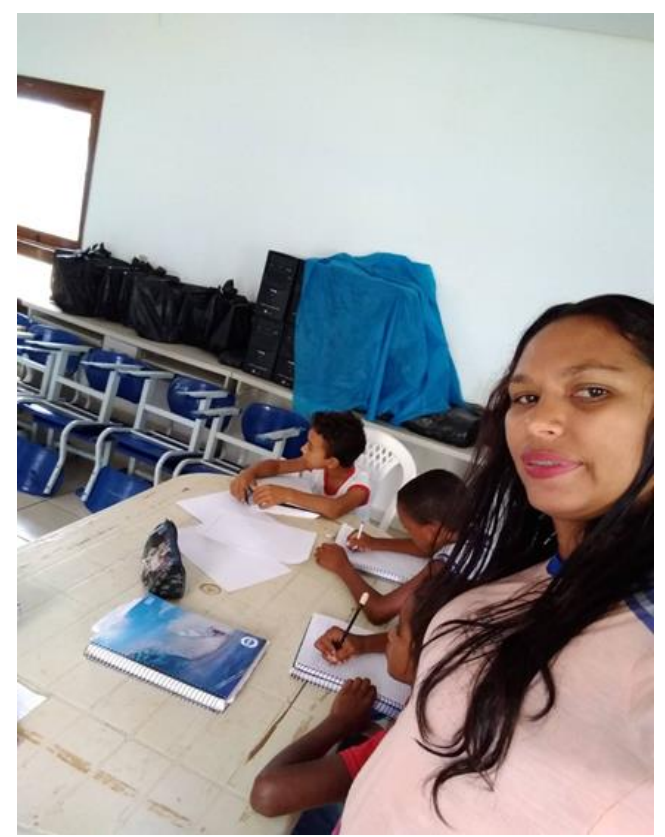

Fonte: Arquivo pessoal 
Quanto ao espaço escolar podemos falar que é bastante acolhedor e amplo, transmite um espaço de segurança, onde os alunos se sentem abraçados e confortáveis. Pode-se dizer que se trata de uma escola com ótima estrutura. $\mathrm{O}$ quadro de funcionários é de grande importância para a escola, pois trata de pessoas que exercem seus cargos com democracia, e buscam sempre o melhor para a escola e seus alunos.

Todas as fases do PRP foram realizadas com grande sucesso. Cada uma proporcionou conhecimentos específicos. Certamente o Programa fortaleceu a parceria entre a universidade e a escola campo de residência, culminado no aperfeiçoamento da prática docente. O programa é um sucesso e muito auxilia na vida acadêmica.

\section{Conclusões}

Concluído com sucesso, constatou-se que o Programa Residência Pedagógica tem uma proposta que envolve residentes, preceptores, escola campo, com um trabalho de parceria e aprendizagem. O PRP possibilidade a qualificação, formando docentes mais cientes do contexto em que atuarão, produtores de conhecimentos, com posturas investigativas e reflexivas acerca da própria prática docente.

O PRP contribui na formação de professores na relação entre universidade e escola campo, desenvolvida através da socialização profissional e pela relação entre teoria e prática. Com relação ao desenvolvimento profissional docente, destaca-se o aprimoramento da prática docente no cotidiano escolar e sua valorização. O programa também proporcionou uma reflexão sobre a prática docente e as novas metodologias de ensino e aprendizagem.

Devido o sucesso do programa e seu benefício para a formação inicial de professores, refletiu-se sobre o acompanhamento dos professores, em sua formação continuada e a importância de estar sempre atualizado.

503 Id on Line Rev. Mult. Psic. V.13, N. 48 p. 491-504, Dezembro/2019 - ISSN 1981-1179 


\section{Referências}

BRASIL. Edital Capes 06/2018 que dispõe sobre a Residência Pedagógica. Disponível em https://www.capes.gov.br/images/stories/download/editais/01032018-Edital-6-2018residência-pedagogica.pdf. Acesso em 19 de Setembro de 2019

LIBÂNEO, José Carlos. Educação escolar, políticas, estruturas e organização. 2 ed. SP: Cortez, 2005

TARDIF, M. As concepções do saber dos professores de acordo com diferentes tradições teóricas e intelectuais (Xerox Pós-graduação PUC), Rio de Janeiro, 2000.

TARDIF, Maurice; LESSARD, Claude. (Orgs.) O ofício de professor: história, Perspectivas e desafios internacionais. 2. Ed. - Petrópolis, RJ: Vozes, 2008.

VEIGA, Ilma Passos Alencastro. Projeto político-pedagógico da escola: uma construção possível. (org) $14^{\mathrm{a}}$ ed. - Papirus, 2002.

Como citar este artigo (Formato ABNT):

SILVA, Damiana Filgueira da; CANUTO, Wêdya Gabriely Pereira; BENTO, Maria das Graças de Oliveira. Experiências da Ambientação do Programa Residência Pedagógica: Conhecendo na Prática. Id on Line Rev.Mult. Psic., Dezembro/2019, vol.13, n.48, p. 491 - 504. ISSN: 1981-1179.

Recebido: $19 / 11 / 2019$

Aceito: 22/11/2019. 